\title{
An audit of ECT in England 2011-2015: \\ Usage, demographics, and adherence to guidelines and legislation
}

\begin{abstract}
Objectives. Electroconvulsive therapy (ECT) continues to be used in England, but without comprehensive national auditing. Therefore information was gathered on usage, demographics, consent, and adherence to the guidelines of the National Institute of Clinical Excellence (N.I.C.E.) and to the Mental Health Act.

Design and Methods. Freedom of Information Act requests were sent to 56 National Health Service Trusts.

Results. Thirty two trusts provided some usable data. Only ten were able to report how many people received psychological therapy prior to ECT in accordance with N.I.C.E. recommendations, with figures ranging from $0 \%$ to $100 \%$. The number of people currently receiving ECT in England annually is between 2,100 - 2,700, and falling. There was a 12-fold difference between the Trusts with the highest and lowest usage rates per capita. Most recipients are still women (66\%) and over $60(56 \%)$. More than a third (39\%) is given without consent; with $30 \%$ of Trusts not adhering to mental health legislation concerning second opinions. At least $44 \%$ were not using validated measures of efficacy, and at least $33 \%$ failed to do so for adverse effects. Only four providing any actual data for positive outcomes or adverse effects. None provided any data on efficacy beyond the end of treatment.
\end{abstract}

Conclusions. National audits should be reinstated. Independent, objective monitoring of adverse effects is urgently required. An investigation into why ECT is still administered excessively to older people and women seems long overdue. 


\section{Practitioner Points:}

- Mental health staff should seek to ensure that all depressed people in their service are offered evidence-based psychological treatments before being offered E.C.T.

- Staff should lobby managers to ensure proper auditing of E.C.T. within their service

- Individuals receiving ECT should be closely monitored for adverse cognitive effects

- Overuse of ECT with women and older people should be avoided

Keywords: Electroconvulsive therapy, auditing, psychological therapy, women, older people, consent, mental health legislation

\section{Introduction}

Although the use of ECT in England, and internationally, has been steadily declining for decades, mapping that decline accurately has been difficult since the Department of Health stopped publishing its national audits of the 1980s and 1990s. Electroconvulsive therapy is still used, on several hundred thousand people internationally every year (Leikne et al., 2009; Read, Bentall, Johnstone, Fosse, \& Bracken, 2013). A review, of 70 studies, found 'large variation between continent, countries and regions in utilization, rates and clinical practice' (Leikne et al. 2012, p. 296). High users include Australia, Belgium, Norway, Sweden and the U.S.A. Financial arrangements also vary. In the UK the vast majority of ECT is administered within the publicly funded National Health Service (Buley, Hodge \& Hailey, 2016), whereas in other countries, including the USA and Australia for example, private psychiatrists play a leading role.

ECT remains one of the most controversial of psychiatric treatments. Several metaanalyses conclude it is an effective treatment for depression (Gabor \& Laszio, 2005; Greenhalgh et al., 2005; Kho et al., 2003; Pagnin et al., 2004; UK ECT Review Group, 2003; 
van der Wurff et al., 2003). A 2010 review, however, noted that none of these meta-analyses identified any evidence that ECT had any benefit, compared to placebo, beyond the end of treatment, and that there is no evidence that ECT prevents suicide (Read \& Bentall, 2010). The most recent review also failed to find a single study showing that ECT is superior to placebo beyond the end of treatment (Read \& Arnold, 2017). The National Institute of Care and Excellence (N.I.C.E.) (2009) has stated that 'Further research is urgently required to examine the long-term efficacy and safety of ECT'. Other reviews (Rasmussen, 2009; Ross, 2006) had reached similar conclusions to the 2010 review, such as 'Rigorously defined endogenously depressed patients did exceptionally well with sham ECT, as well as with real ECT' (Rasmussen, p.59). The controversy also focuses on the extent to which ECT causes long-lasting memory dysfunction, and increases mortality (Breggin, 2008; Fosse \& Read, 2009; Read et al., 2013; Rose et al., 2003, 2004; Sackeim, 2007).

The controversy includes the issues of when ECT should be used, and on whom. Some consider it the treatment of choice for several disorders. Others argue it should never be used. A common position is that it should be used only as a last resort, and only when other treatments have failed. The UK government guidelines (National Institute for Clinical Excellence 2009, 2017) promotes this position. N.I.C.E. guidelines (2017) currently state:

Consider ECT for acute treatment of severe depression that is life-threatening and when a rapid response is required, or when other treatments have failed.

Do not use ECT routinely for people with moderate depression but consider it if their depression has not responded to multiple drug treatments and psychological treatment.

This is repeated, almost verbatim by the UK's Royal College of Psychiatry (2017). 
Controversy is also to be found about why ECT has consistently been targeted at women and older people, internationally, and whether the frequent use of compulsion is ethical or evidence-based (Breggin, 2008; Read et al., 2013). In England the Mental Health Act 2007 revised the legislation relating to treatment without consent (s58A), introducing additional safeguards, and guidelines to Second Opinion Appointed Doctors (SOADs) (Department of Health, 2009). These safeguards include the requirement that when detained patients are deemed incapable of giving consent the SOAD must testify that it is appropriate for the patient to receive ECT. Prior to this the SOAD must consult two other persons, one of which must be 'a nurse concerned with the patient's medical treatment' and the second 'another person professionally concerned with the patient's medical treatment who is neither a nurse nor a doctor'.

N.I.C.E. guidelines (2017) also state:

Clinical status should be assessed following each ECT session and treatment should be stopped when a response has been achieved, or sooner if there is evidence of adverse effects.

This study, therefore, aimed to assess:

- whether N.I.C.E. guidelines about psychological treatments being tried before ECT, and about monitoring negative and positive outcomes, are being followed.

- whether usage is increasing, decreasing or remaining steady

- whether the treatment continues to be disproportionately used on women and old people

- how much compulsion is being used, and whether legislation regarding Second Opinion Appointed Doctors (SOADs) is being complied with 


\section{Method}

These research questions were addressed using a cross sectional, retrospective design targeted at all publicly funded ECT providers in England, addressing ECT usage during 2011, 2013 and 2015. These years were selected so as to assess both recent practice and recent change over time, while maximising the probability of the Trusts being able to provide data. Ethical approval was not required as there was no interaction with patients.

\section{Data gathering}

In November 2016, a Freedom of Information (FOI) Act request was sent to the Freedom of Information Officer of all 60 publicly funded providers of mental health services in England, including 56 National Health Service [NHS] Trusts. The Act entitles anyone to request information from any public sector body. Our request consisted of the following questions, developed specifically for this study to address our research questions:

1. For each of the years 2011, 2013 and 2015, how many patients received ECT (Please break down the three answers in this section for males/females)

a) How many of these were under 18?

b) How many of these were over 60?

2. For each of the years 2011, 2013 and 2015, what were the documented primary diagnoses when given ECT? Depression; Psychosis; Anxiety Disorder; Personality Disorder; Other

3. For each of the years 2011, 2013 and 2015, how many patients were given ECT without consent?

4. Currently when a patient does not consent what professions does the SOAD consult? 
5. How many people had ECT in 2015 without receiving a N.I.C.E. recommended psychological therapy?

6. In 2015 what were the measures used, and results for, in relation to a) Clinical outcomes for ECT; b) Adverse effects of ECT.

\section{Participants}

None of the four non-NHS providers provided data, with three explaining they were not obliged to do so because they were 'not a public authority' and one failing to respond at all. Thirty two of the 56 NHS Trusts $(57.1 \%)$ provided some usable data. The number replying to specific questions ranged from 32 (2015 ECT totals) to four (outcome data).

\section{Data analysis}

Being essentially an audit, most of the data is presented in descriptive format. The exceptions were the use of two-tailed t-tests to determine if the means of the annual totals differ, and Spearman Rank correlation coefficients to assess the stability of differential usage of ECT by the various Trusts over time.

\section{Results}

\section{Psychological therapy}

Only ten Trusts answered 'How many people had ECT without receiving a N.I.C.E. recommended psychological therapy in 2015?' Seven offered no explanation for not answering. The other 15 used one or more of the following explanations: 'not recorded' (7); recorded but not collated - so not easily accessible (5); beyond the amount of information that can reasonably be expected to be provided without charging a fee (Section 12 of the FOI Act) (6). 
The ten Trusts reported that 210 of 767 people (27.4\%) received ECT without first receiving psychological therapy (see Table 1). The range was from $100 \%$ in two Trusts (Humber, South Staffordshire \& Shropshire) to $0 \%$ in four (Camden, Hertfordshire, Kent \& Medway, West London).

\section{INSERT TABLE 1 ABOUT HERE}

\section{Numbers}

Twenty nine Trusts provided the number of people given ECT for 2011, 2013 and 2015. The three others only provided data for 2015 . The total number was 4,536 , producing an average of 50.40 people per Trust per year. The range was from four (Black Country in 2011) to 142 (Cheshire \& Wirral in 2011), a 35 fold difference. The range across all 32 Trusts for the most recent year (2015) was from eight (West London) to 121 (Surrey \& Borders), a 15fold difference. Among the 29 providing data for all three years the average per year ranged from 8.0 (Black Country) to 126.7 (Surrey \& Borders), also a 15-fold difference.

Table 1 presents the same data in relation to the sizes of the populations served by the Trusts. The average number of people receiving ECT across the three years, per 100,000 of the total population of each Trust, ranged from 1.03 (Black Country) to 12.70 (North Staffordshire), a 12-fold difference. Two other Trusts had rates above 10/100,000: Worcestershire (12.38) and Cheshire \& Wirral (12.23). Four other Trusts had rates less than 2.5/100,000: Camden \& Islington (2.26); Kent \& Medway (2.08); West London (2.05) and South West London \& St George's (1.2).

The average number of ECT recipients per Trust for the three years $(n=29)$ were: 2011 $48.72 ; 2013-54.37 ; 2015-47.76$. None of the differences between the three pairs of means were significantly different. 
The pattern of differences between Trusts remained stable over time. Spearman rank correlation coefficients between the three pairs of years were: $2011-2013=0.90 ; 2013$ $2015=0.89 ; 2011-2015=0.87$; these were all significant at the $\mathrm{p}<.0001$ level.

\section{Gender and age}

Twenty eight Trusts provided gender data, for 3,901 people. Of these, 2,579 (66.1\%) were women. The range was from $48.8 \%$ (West London) to $85.7 \%$ (South Staffordshire \& Shropshire). In 25 of the 28 Trusts (89\%) more than 55\% were women. In fifteen (54\%) women were at least twice as likely to receive ECT as men $(\leq 66.7 \%)$. Women in Oxford were three times more likely than men to receive ECT (75.1\%); and six times more likely in South Staffordshire \& Shropshire.

Twenty nine Trusts answered the age-related questions. Of 3,925 ECT recipients, 2,216 $(56.5 \%)$ were over 60 . Table 1 shows that the lowest rates were in Camden $(22.2 \%)$ and Greater Manchester (31.0\%), and the highest in South Staffordshire \& Shropshire (82.1\%), Barnet, Enfield \& Haringey (75.5\%) and Birmingham \& Solihull (73.5\%). In 21 out of 29 Trusts (72\%) at least half of ECT recipients were aged over 60.

Only $0.2 \%$ of ECT recipients were children, i.e. aged under 18 . Only five Trusts had used ECT on children in any of the three years. The highest rate across the three years was in Birmingham \& Solihull (2.6\%, 4 out of 155$)$.

\section{Diagnoses}

Data on 2,564 people, from 22 Trusts, showed that most people were diagnosed with Depression $(2,186 ; 85.3 \%)$. The range was from 35.0\% (Black Country) and 40.5\% (South Staffordshire \& Shropshire) to 100\% for three Trusts (Coventry \& Warwickshire, Dorset, and West London). Other diagnostic groupings were: Psychosis (135, 5.3\%); Bipolar/Mania (51, 
2.0\%); Personality Disorder (39, 1.5\%), Anxiety (18, 0.7\%), and Dementia (3, 0.1\%). Twelve of the 22 Trusts $(54 \%)$ administered ECT to at least one person with a primary diagnosis for which ECT is not indicated (Anxiety - 7 Trusts; Personality Disorder - 6; Dementia - 1). In South Staffordshire \& Shropshire, 23 of 84 ECT recipients (27.4\%) were diagnosed with Personality Disorder.

\section{Consent}

Data on 2,987 people, from 22 Trusts, indicated that 1,157 (38.7\%) had been given ECT without their consent. Table 1 shows that this ranged from $15.3 \%$ (Surrey \& Borders) to 72.2\% (Hertfordshire) and 100\% (Black Country).

Professions used by Second Opinion Appointed Doctors, to certify ECT in the case of people deemed to lack capacity to give consent were: OTs (80\%); nurses $(65 \%)$; physiotherapists (45\%); clinical psychologists (30\%); pharmacists (30\%); doctors (15\%); social workers $(15 \%)$; dieticians $(5 \%)$; and ward managers $(5 \%)$. Fourteen out of the 20 Trusts that provided this data $(70 \%)$ were using the combination of professionals required by the Mental Health Act.

\section{Efficacy}

Methods. Nine Trusts (28\%) provided no information about the measures they used in relation to clinical outcomes. The most commonly used, by 16 of the $23(70 \%)$ that did provide information was the Clinical Global Impressions (CGI) scale, in which a single clinician subjectively assesses severity of psychopathology, and change from start of treatment, on seven-point scales. Table 1 shows that 13 of the 23 Trusts (56.5\%) used one or more of the following validated scales (see Table 1): Mini Mental State Examination [MMSE] (5 Trusts); Montgomery-Åsberg Depression Rating Scale (4); Hamilton Depression 
Rating Scale (3); Hospital Anxiety and Depression Scale (1); Health of the Nation Scale (1); Beck Depression Inventory (1). Six used only the subjective CGI scale. The other four described a range of other subjective approaches to assessing efficacy, such as 'ward observations' and 'psychiatrist review'.

Measures and assessments were administered regularly during treatment, but no Trusts mentioned any follow up assessments after the end of treatment. None referred to any independent assessments, at any time by anyone not involved in delivering ECT.

Data. Only four of the 33 Trusts (12.1\%) provided any actual data about clinical outcomes. Two provided some data from the seven point CGI scale (anchor points 'significantly improved' and significantly worse'). Cornwall reported findings for after each individual administration of ECT rather than for each patient. Their findings, for 310 administrations (an average of ten per person) were: Significantly improved - 21 (6.8\%); Much improved - 96 (31.0\%); Minimally improved - 96 (31.0\%); No change - 81(26.1\%); Minimally worse - 7 (2.3\%); Much worse - 2 (0.6\%); Significantly worse - 1 (0.3); and six not assessed. Coventry \& Warwickshire, reporting on people rather than individual treatments, wrote: ' $100 \%$ CGI 6 or 7 prior to trt (severely ill/amongst the most severely ill). 95\% CGI score of 1,2 or 3 post course (Very much improved, much improved, improved). 5\% 4 no change'.

Coventry \& Warwickshire also reported that 'All Hospital Anxiety and Depression Scale scores improved at end of course to varying degrees'. Greater Manchester West, who had used the CGI and the Montgomery-Åsberg Depression Rating Scale, simply reported that 'all patients reported improvement with ECT'. Surrey \& Borders, who had provided no information about how efficacy had been measured, stated ' $80-90 \%$ improvement'. No follow up data, beyond the end of treatment, was reported by any Trusts. 


\section{Adverse effects}

Measures. Eleven Trusts failed to provide any information about what measures of adverse effects were used. Of the 21 providing information, 14 reported using one or more validated scale, most commonly the MMSE (8) and the Montreal Cognitive Assessment Measure (5). Two used the Addenbrookes Cognitive Examination, and two used the Six-item Cognitive Impairment Test [6CIT]. The other seven Trusts offered more general comments such as 'short term memory is monitored along with physical health assessment'. Measures and assessments were administered regularly during treatment.

Four Trusts mentioned assessment beyond the end of treatment. Only three Trusts included information about who did the assessing: 'Patient's own views and their treating clinician's assessment', 'Consultant reviews' and 'Subjective questions, gathering the opinions of staff, carers, relatives'. None referred to any assessments by anyone not directly involved.

Data. Only four Trusts provided actual data on adverse effects. Coventry \& Warwickshire reported that of their 54 ECT recipients ' $4.9 \%$ scored above 24 using MMSE post treatment (normal range)', indicating that $95.1 \%$ had mild, moderate or severe cognitive impairment following ECT. Greater Manchester West reported that of their 40 ECT patients, ' 6 short term memory loss (resolved after 2-3 days); seven patients had headaches post ECT resolved with analgesics'.

Surrey and Borders reported that their 121 patients experienced only 'headaches' and 'nausea'. Leicestershire, with 47 ECT recipients, stated 'there were no adverse effects of ECT on any patient in $2015^{\prime}$. No Trusts reported any follow up data beyond the end of treatment.

\section{Discussion}




\section{Psychological therapy}

Unfortunately the data gathered in the current study cannot reliably answer the question 'How many people had ECT without receiving a N.I.C.E recommended psychological therapy?' because only ten of $32(31 \%)$ responded to this question. This represents just $18 \%$ of the 56 Trusts that were asked the question. Failure to record or collate this information suggests that most Trusts are not interested in, or aware of, N.I.C.E guidelines on this matter. The fact that in at least two Trusts ECT was given to everyone (158 in total) without any of them having first received psychological therapy is a flagrant breach of N.I.C.E guidelines. It seems some clinicians remain unconvinced of the need for an integrated, evidence-based approach involving the non-medical treatments recommended by N.I.C.E.

N.I.C.E. supports its recommendations for the use of psychological treatments for depression with a range of studies and reviews, including a meta-analysis that examined 17 randomized control trials involving over 3000 participants and found an overall benefit of psychological therapies compared with usual care, particularly for CBT-type interventions (van t'Hof, Cuijpers, Waheed, \& Stein, 2011). Unlike ECT, psychological treatments can teach new techniques which last beyond the end of treatment and which may contribute to self help and early recognition and intervention. Psychological treatments involve active involvement rather than the passive role of a 'patient' receiving a 'treatment' and, hopefully, a collaborative relationship of the kind clients might need to prevent or overcome further 'episodes'. Furthermore E.C.T. cannot address the various well documented psycho-social causes of depression such as loss, neglect and abuse (Cromby, Harper \& Reavey, 2013; Kendler, Hettema, Butera, Gardner, \& Prescott, 2003). One additional reason why there is so much evidence for the efficacy of psycho-social interventions and so little for E.C.T. relates to the implied messages about causation that accompany the treatments. Assumptions that one's difficulties are caused by their being something wrong with one's brain are associated 
not only with greater prejudice from other people, but with pessimism about recovery and less effort to improve one's own situation (Kvaale, Haslam, Gottdiener, 2013; Read, Haslam, Sayce, \& Davies, 2006).

\section{Numbers}

A comprehensive survey by the Royal College of Psychiatrists (RCP) estimated that 27,000 people received ECT in Great Britain in 1980, and that usage had halved since the early 1970s (Pippard \& Ellam, 1981). Department of Health reports for England $(1989,1999)$ show that the number of individual administrations of ECT fell from 159,600 in 1980 to 109,707 in 1989 , and then to 65,928 in 1999 . If the average number of administrations per course of treatment was six, this would mean that the number of people given ECT in England had fallen to about 18,000 in 1989, and 11,000 in 1999. Extrapolating from the last report by the Department of Health (2003), on the first quarter of 2002, produces an annual figure of 9,200 people.

An ECT Accreditation Service (ECTAS) survey estimated that the number of people receiving ECT in England in 2006 had continued to fall, substantially, to about 1,300 (Cresswell et al., 2007). A subsequent ECTAS report gathered responses from 78 of 104 ECT clinics in England and Wales, for 2012/2013 (Cresswell \& Hodge, 2013). It can be estimated that in the 104 clinics 2,305 people received ECT, or 2,527 if one includes those receiving more than two courses during the year. Given that there were 71 English clinics reporting, it can be further estimated that about 2,385 of these courses occurred in England.

The current study can also provide only an estimate. The current number of N.H.S. mental health Trusts is 56. Multiplying the average number of annual ECT recipients for 29 Trusts for the years 2011, 2013 and 2015 combined (50.40) by 56, produces a total of 2,822 people, with totals for each year as follows: 2011- 2,728; $2013-3,045 ; 2015-2,675$. 
A 2017 article in the Guardian newspaper, inaccurately headlined 'Electroconvulsive therapy on the rise again in England', reported on the responses of 44 of 56 English mental health Trusts to an FOI request (Davies \& Duncan, 2017). The article reported that in those 44 Trusts 'more than 2,200' people received ECT in 2015/2016 and that this was a rise from 2012/2013. The actual numbers for each of the four years covered were: 2012/13 - 2070; 2013/14 - 2229; 2014/15 - 2149; and 2015/16 - 2189 (personal communication, 2017). These variations are smaller than those found in the current study, which produced an increase of $11.2 \%$ in ECT usage over two years followed by a decrease of $12.2 \%$ during the subsequent two years, with neither of those changes approaching significance. So the change over a three year period noted by the Guardian is actually part of the 'considerable fluctuation over the last four years' acknowledged in the same article.

Extrapolating from the 44 responding Trusts to all 56 Trusts produces estimates ranging from 2,635 to 2,837 , and an average of 2,748 people per year for the period 2012/13 to $2015 / 16$. This is similar to the 2,822 figure produced by the current study.

Combining the current study with the ECTAS reports for 2006 and 2012/2013 and the Guardian survey, it is reasonable to assume that the number of people in England receiving ECT annually within NHS Trusts had continued its steady decline until around 2006 (to a low of about 1,300), but then increased and stabilised for a few years at about double that number. It remained between 2,300 and 3,100 from 2011 to 2015/16. The latest ECTAS report, for 2016/17, has just reported, however, a 'decline from previous years', to 2,135 (Buley, Copland \& Hodge, 2017). The decline of $12.2 \%$ from 2013 to 2015 in the current survey, although not statistically significant by itself, is consistent with the ECTAS conclusion that, after a brief upturn, the forty year decline in the use of ECT in England has recommenced but has not yet reached the 2006 low point of 1,300 . 
Variation. This large decline over several decades is matched by most other countries, but, as noted earlier, there is large variation between countries (Leikne et al., 2012). Huge regional variation within countries has also been mentioned in most reports for several decades. The 1980 RCP survey found five-fold differences in usage between regions of Great Britain and 17 fold differences between hospitals. Variations are not reported by ECTAS. The current study, however, found a 12-fold difference per 100,000 between the highest and lowest Trusts. As the 1980 RCP report suggested, this is probably explained by the wide range of personal opinions about ECT held by individual psychiatrists.

\section{Gender and age}

The current study's finding that women are twice as likely to receive ECT is remarkably consistent, in most countries, for decades (Leikne et al., 2012; Read et al., 2013). The 1981 RCP report found that $69 \%$ of ECT recipients were women. The 2003 Department of Health figure was 70\%, and the latest ECTAS survey reported 66\% (Buley et al., 2017). These findings parallel the similar levels of disproportionate current prescribing of antidepressants and, before that, benzodiazepines, to women. The most recent ECTAS report found that the proportion is even higher for maintenance ECT - 74\%.

The disproportionate use of ECT on older people, found in the current study, is also consistent with many other findings, internationally, over many decades (Leikne et al., 2012; Read et al., 2013). In the 2012/2013 ECTAS survey, for instance, the average age was 62 (Cresswell \& Hedge, 2013). In the latest ECTAS report 59\% were 60 or over, and 35\% were 70 or over (Buyley et al., 2017); with even higher proportions for maintenance ECT: 68\% 60 or over, $50 \% 70$ or over. The mean age was 61 and the mean for maintenance ECT was 66.

If these findings about age and gender are partly or completely explained by higher levels of depression then one might wonder whether treatments that addressed the social 
causes of the gender's or age group's greater distress might be deployed rather than treatments that are blind to such causal disparities. Poverty and loneliness come to mind as possible candidates.

The largest prospective study of cognitive dysfunction caused by ECT (Sackeim et al., 2007), found that $12 \%$ met the criterion for 'marked and persistent retrograde amnesia', and that women and older people, the two groups who receive ECT disproportionately, had particularly high rates. The researchers pointed out women have a lower seizure threshold and electrical dosage was often not adjusted accordingly. The finding that older people are particularly susceptible to the cognitive dysfunction caused by administering electric shocks to the brain was not new (Sackeim, 2004), and is consistent with findings that they are also particularly susceptible to many of the adverse effects of antidepressant drugs (Coupland et al., 2011). This set of findings suggests that psychological therapies may be particularly appropriate for older people, and that it is particularly essential that they are not offered E.C.T. before being offered psychological therapy.

\section{Diagnosis}

The vast majority of diagnoses were depression (85\%), which is broadly consistent with the most recent ECTAS report (90\%). The ECTAS report, however, identified none of the diagnoses for which ECT is not recommended that were identified in the current study (in just over half the Trusts). This may be because of bias created by ECTAS using forced choice responses 'based on NICE guidance' (Buyley et al.). The use of ECT on people diagnosed with Personality Disorders, in six Trusts, is of concern.

\section{Consent}


A substantial minority, 38\%, is still being given ECT against their will. As with previous studies, there is enormous variation, from $0 \%$ to $100 \%$. It appears the proportion given ECT without giving consent is rising (Buley et al., 2017). The proportion, including 'emergencies', was $18 \%$ in 1999 and 20\% in 2002 (Department of Health, 1999, 2003). ECTAS reported that in 2012/13 35\% were detained under the Mental Health Act and deemed incapable of giving consent; by $2016 / 2017$ this figure had risen to $41 \%$

It is of concern that six of the 20 Trusts that provided relevant information appeared to be in breach of section 58A of the Mental Health Act in that they were not using the correct combination of professionals to provide second opinions. The ECTAS reports do not monitor this.

\section{Efficacy}

The most commonly used method for assessing efficacy was the Clinical Global Impressions Scale. This very basic scale, which takes just a few seconds to complete, seems inadequate to assess an invasive and potentially dangerous intervention. Furthermore, there is no reason to believe that this inevitably subjective and simple approach to assessment was conducted by anyone other than the treating staff, who are necessarily potentially biased. There was no evidence, from any Trusts, of any attempt at independent assessments. There was also no evidence of any assessment of whether any gains perceived by the clinicians lasted beyond the end of treatment. The 13 Trusts that used validated scales are, however, to be commended.

That only four Trusts could provide any actual data, and that none could provide any follow-up data, is of serious concern. It suggests that most Trusts do not collate this data, and therefore are not able to review whether their use of ECT is effective. Perhaps they just assume it is helping. The rates of improvement attributed to ECT during treatment by three of 
the four Trusts, or at least by their ECT clinicians, $80 \%-90 \%, 95 \%-100 \%$, and $100 \%$, were, when compared to the literature, incredible.

The 'Clinical Outcomes' section of the latest ECTAS survey reports only CGI scores in (Buyley et al., 2017). It reports no data using validated measures or independent observers, and no data beyond the end of treatment.

This pervasive failure to adequately assess the effectiveness of this controversial and intrusive intervention matches the failure of the psychiatric research community to do so. There has not been a single study of ECT compared to placebo for over thirty years, despite the fact that none of the ten that were conducted prior to 1986 found ECT to be any better than placebo beyond the end of treatment, and five found no benefit even during the treatment period (Read \& Bentall, 2010; Read et al., 2013; Read \& Arnold, 2017). The continued use of E.C.T., and the huge variation from one locality to another, relies on the genuinely held beliefs of the dwindling number of psychiatrist who use it rather than on any evidence of its effectiveness, for depression, psychosis or suicide prevention. The psychosocial context within our mental health services that promotes the use of ECT as opposed to psychological treatments, regardless of the research evidence, includes an over reliance on an ideologically driven, simplistic 'medical model', supported by the profession of psychiatry (biological psychiatrists in particular) and the pharmaceutical industry (de Wattignar \& Read, 2009; Mosher, Gosden \& Beder, 2013). This narrow, unbalanced approach is partly maintained, however, by the understandable human need to avoid listening to distressing and depressing experiences and feelings, and to the social causes thereof (Boyle, 2011; Read \& Dillon, 2013; Speed, Moncrieff \& Rapley, 2014).

\section{Adverse effects}

N.I.C.E. guidelines (2017) state: 
Cognitive function should be monitored on an ongoing basis, and at a minimum at the end of each course of treatment

That eleven of 32 Trusts (34\%) could not readily report what measures were in use to assess adverse effects is worrying. The 14 Trusts (44\%) that reported using one or more validated scale are clearly taking their ethical responsibilities more seriously. Four Trusts (15\%) even referred to assessment of adverse effects beyond the end of treatment, and are to be commended for doing so.

That only four Trusts could provide any actual data on adverse effects is particularly worrying. Overall when asked about adverse effects only two trusts out of 56 could provide any data about the best documented long term side effects of ECT, cognitive dysfunction and memory loss. The percentage of patients reported to be experiencing cognitive dysfunction by the only two Trusts providing relevant data ranged from $15 \%$ to $95 \%$. No Trusts reported any follow up data on cognitive dysfunction after the end of treatment. These findings suggest that ECT clinicians and their managers are unaware of, or disinterested in, the memory dysfunction that follows almost every ECT treatment, at least temporarily, and which is 'marked and persistent' for at least one in eight (Sackeim et al., 2007) and probably far more (Breggin, 2008; Fosse \& Read, 2009; Read et al., 2013; Rose et al., 2003, 2004).

\section{Recommendations}

A return to comprehensive national annual audits seems urgently needed. These should include attention to compliance with N.I.C.E. guidelines and mental health legislation. In the meantime all mental health service providers must take responsibility for monitoring their own adherence to government guidelines and the law, and should familiarise themselves with 
the research literature on the long term benefits and adverse effects of this controversial treatment. A multidisciplinary investigation into the ongoing excessive use of ECT on women and older people seems long overdue.

\section{Limitations}

An obvious limitation is that data was received from only 32 Trusts, and that responses fell as low as four for data about actual outcomes - positive and negative. These latter response rates, however, constitute important findings in their own right, about whether Trusts are recording and collating the effects (however poorly measured) of such a controversial treatment. Previous surveys of Trusts about ECT, by ECTAS, produced higher response rates (see above), but our lower rate is partly mitigated by gathering data for each of three years, spanning five years.

The study generated no data from service providers other than NHS Trusts. It seems particularly problematic that some providers are operating beyond the jurisdiction of the FOI Act. This represents an uneven playing field for NHS providers and private organisations in relation to costs and accountability.

Declaration of interest: The authors report no conflicts of interest. The authors alone are responsible for the content and writing of the paper.

\section{References}


Boyle, M. (2011). Making the world go away, and how psycholgy and psychiatry benefit (pp. 27-43). In M. Rapley, J. Moncrieff, J. Dillon (eds.). De-medicalising Misery. New York: Palgrave.

Breggin, P. (2008). Brain-disabling Treatments in Psychiatry. New York: Springer.

Buley, N., Copland, E., \& Hodge, S. (2017). ECT Minimum Dataset 2016-17: Activity Data Report - England, Wales, Northern Ireland \& Republic of Ireland. London: Electroconvulsive Therapy Accreditation Service.

Coupland, C., Dhiman, P., Morriss, R., Arthur, A., Barton, G. \& Hippisley-Cox J. (2011). Antidepressant use and risk of adverse outcomes in older people: population based cohort study. British Medical Journal, 343: d4551. doi:10.1136/bmj.d4551

Cresswell, J. \& Hodge S. (2013). ECT Minimum Dataset Activity Data Report - England \& Wales 1 April 2012 - 31 March 2013. London: Electroconvulsive Therapy Accreditation Service.

Cresswell, J., Hood, C. \& Lelliott, P. (2007). Second National Report: October 2005 October 2007. Electroconvulsive Therapy Accreditation Service, 2007.

Cromby, J., Harper, D. \& Reavey, P. (2013). Sadness and worry. In J. Cromby, D. Harper, P. Reavey (Eds.) Psychology, Mental Health and Distress (pp. 193-218). London: Palgrave.

Davies, N. \& Duncan, P. (2017). Electroconvulsive therapy on the rise again in England. The Guardian, April 17.

Department of Health. (1989). ECT: England - Financial year 1988/1989. London: Government Statistical Service.

Department of Health. (1999). ECT: Survey Covering the Period from January 1999 to March 1999. England. London: Government Statistical Service.

Department of Health. ECT: Survey Covering the Period from January 2002 to March 2002, England. London: Department of Health. 
Department of Health, Ministry of Justice. (2009). Mental Health Act 2007, Chapter 12: Explanatory Note. London: Department of Health, Ministry of Justice.

de Wattignar S. \& Read, J. (2009). The pharmaceutical industry and the internet: Are drug company funded depression websites biased? Journal of Mental Health, 18, 1-10. doi: $10.3109 / 09638230902968183$

Fosse, R. \& Read, J. (2013). Electroconvulsive treatment: Hypotheses about mechanisms of action. Frontiers in Psychiatry, 4, 94-103. doi:10.3389/fpsyt.2013.00094

Greenhalgh, J., Knight, C., Hind, D., Beverley, C. \& Walters S. (2005). Clinical and costeffectiveness of electroconvulsive therapy for depressive illness, schizophrenia, catatonia and mania. Health and Technology Assessment, 9, 1-170.

Kendler, K., Hettema, J., Butera, F., Gardner, C. \& Prescott, C. (2003). Live event dimensions of loss, humiliation, entrapment, and danger in the predictin of onsets of major depressino and generalized anxiety. Archives of General Psychiatry, 60, 789-796. doi:10.1001/archpsyc.60.8.789

Kho, K., van Vreewijk, M., Simpson, S. \& Zwinderman, A.( 2003). A meta-analysis of electroconvulsive therapy in depression. Journal of ECT, 19, 139-147.

Kvaale, P., Haslam, N. \& Gottdiener, W. (2013). The 'side effects' of medicalization: A meta-analytic review of how biogenetic explanations affect stigma. Clinical Psychology Review, 33, 782-794. doi:10.1016/j.cpr.2013.06.002

Leikne, K., Jarosh-von Schweder, L. \& Hoie, B. (2012). Contemporary use and practice of electroconvulsive therapy worldwide. Brain and Behaviour, 2, 283-344. doi:10.1002/brb3.37

Mosher, L. Gosden, R. \& Beder, S. (2013). Drug companies and 'schizohrenia': Unbridled capitalism meets madness. In J. Read \& J. Dillon (Eds.), Models of Madness: 
Psychological, Social and Biological Approaches to Psychosis (pp. 125-140). London: Routledge.

National Institute of Care and Excellence. (2009). Guidance on the Use of Electroconvulsive Therapy: Technology Appraisal Guidance TA59. London: N.I.C.E.

National Institute of Clinical Excellence. (2017). Depression in Adults: Recognition and Management. https://www.N.I.C.E. .org.uk/guidance/cg90/chapter/1-Guidance. Accessed April 24, 2017.

Pagnin, D., de Queiroz, V., Pini, S. \& Cassano, G. (2004). Efficacy of ECT in depression: A meta-analytic review. Journal of ECT, 20, 13-20.

Pippard, J. \& Ellam, L. (1989). ECT in Great Britain, 1980. London: Gaskell.

Rasmussen, K. (2009). Sham electroconvulsive therapy studies in depressive illness: A review of the literature and consideration of the placebo phenomenon in electroconvulsive therapy practice. Journal of ECT, 25, 54-59. doi:0.1097/YCT.0b013e3181719b23

Read, J. \& Arnold, C. (2017). Is electroconvulsive therapy for depression more effective than placebo? A systematic review of studies since 2009. Ethical Human Psychology and Psychiatry, in press.

Read, J. \& Bentall, R. (2010). The effectiveness of electroconvulsive therapy: A literature review. Epidemiology and Psychiatric Sciences 19, 333-347. doi:10.1017/S1121189X00000671

Read, J., Bentall, R., Johnstone, L., Fosse, R. \& Bracken, P. (2013). Electroconvulsive therapy. In J. Read \& J. Dillon (Eds.), Models of Madness: Psychological, Social and Biological Approaches to Psychosis (pp. 90-104). London: Routledge.

Read, J. \& Dillon, J. (2013). Creating evidence-based, effective and humane services: Overcoming barriers to a paradigm shift. In J. Read \& J. Dillon (Eds.), Models of 
Madness: Psychological, Social and Biological Approaches to Psychosis (pp. 392-407). London: Routledge.

Read, J., Haslam, N., Sayce, L. \& Davies, E. (2006). Prejudice and schizophrenia: A review of the 'Mental illness is an illness like any other' approach. Acta Psychiatrica Scandinavica, 114, 303-318. doi:10.1111/j.1600-0447.2006.00824

Rose, D., Fleischman, P. \& Wykes, T. (2004). Consumers' views of electroconvulsive therapy: A qualitative analysis. Journal of Mental Health, 13, 285-293. doi:10.1080/09638230410001700916

Rose, D., Fleischmann, P., Wykes, T., Leese, M. \& Bindman, J. (2003). Patients' perspectives on electroconvulsive therapy: Systematic review. British Medical Journal, 326, 1363. doi:10.1136/bmj.326.7403.1363

Ross, C. (2006). The sham ECT literature: implications for consent to ECT. Ethical Human Psychology and Psychiatry, 8, 17-28. doi:org/10.1891/ehpp.8.1.17

Royal College of Psychiatry. (2017). Mental Health Information. http://www.rcpsych.ac.uk/mentalhealthinformation/therapies/electroconvuls ivetherapy,ect.aspx. Accessed April 24, 2017.

Sackeim, H. (2004). Electroconvulsive therapy in late-life depression. In S. Roose, H. Sackeim (Eds). Late-Life Depression (pp 241-278), Oxford University Press: New York.

Sackeim, H., Prudic, J., Fuller, R., Keilp, J., Lavori, P. \& Olfson, M. (2007). The cognitive effects of ECT in community settings. Neuropsychopharmocology, 32, 244-254.

Speed, E., Moncrieff, J. \& Rapley, M. (Eds.) (2014). De-Medicalizing Misery II: Society Politics and the Mental Health Industry. London: Palgrave.

UK ECT Review Group. (2003). Efficacy and safety of ECT in depressive disorders. Lancet 361, 799-808. doi:10.1016/S0140-6736(03)12705-5 
van der Wurff, F., Stek, M., Hooogendijk, W. \& Beekman A. (2003). Electroconvulsive therapy for the depressed elderly. Cochrane Database of Syst Rev 2003, Issue 2, CD003593. doi:1002/14651858.CD003593

van t'Hof, E., Cuijpers, P., Waheed, W., \& Stein, D. (2011) Psychological treatments for depression and anxiety disorders in low- and middle-income countries: a meta-analysis.

African Journal of Psychiatry 14, 200-207. Doi:org/10.4314/ajpsy.v14i3.2 
Table 1. ECT usage, demographics, consent and other monitoring of the 32 Trusts responding to Freedom of Information requests.

\begin{tabular}{|c|c|c|c|c|c|c|c|c|c|}
\hline \multirow{2}{*}{$\begin{array}{l}\text { National Health } \\
\text { Service Trusts } \\
\text { N Staffordshire } \\
\text { Combined Healthcare }\end{array}$} & \multirow{2}{*}{$\begin{array}{c}\text { ECT per } \\
100,000 \\
12.7\end{array}$} & \multirow{2}{*}{\begin{tabular}{|c|}
$\%$ \\
Female \\
73.2 \\
\end{tabular}} & \multirow{2}{*}{$\begin{array}{c}\% \\
\text { Over } \\
60 \\
65.9\end{array}$} & \multirow[t]{2}{*}{$\begin{array}{c}\text { \% } \\
\text { Without } \\
\text { consent }\end{array}$} & \multirow[t]{2}{*}{$\begin{array}{c}\% \\
\text { Offered } \\
\text { Psych- } \\
\text { ology }\end{array}$} & \multicolumn{2}{|c|}{$\begin{array}{l}\text { Effectiveness } \\
\text { Valid } \\
\text { Measure Data }\end{array}$} & \multicolumn{2}{|c|}{$\begin{array}{l}\text { Adverse Effects } \\
\text { Valid } \\
\text { Measure Data }\end{array}$} \\
\hline & & & & & & yes & & yes & \\
\hline $\begin{array}{l}\text { Worcestershire } \\
\text { Health \& Care }\end{array}$ & 12.4 & 65.9 & 60.1 & 46.2 & & & & & \\
\hline $\begin{array}{l}\text { Cheshire \& Wirral } \\
\text { Partnership }\end{array}$ & 12.2 & 68.9 & & & & yes & & yes & \\
\hline $\begin{array}{l}\text { Surrey \& Borders } \\
\text { Partnership }\end{array}$ & 9.7 & 67.1 & 40.5 & 15.3 & & & yes & no & yes \\
\hline $\begin{array}{l}\text { Leeds \& York } \\
\text { Partnership }\end{array}$ & 9.1 & 64.8 & 71.4 & & & & & & \\
\hline $\begin{array}{l}\text { Nottinghamshire } \\
\text { Healthcare }\end{array}$ & 7.9 & & 39.8 & & & yes & & yes & \\
\hline $\begin{array}{l}\text { Dorset Healthcare } \\
\text { University }\end{array}$ & 7.4 & & 71.2 & 40.0 & & no & & yes & \\
\hline $\begin{array}{l}\text { SW Yorkshire } \\
\text { Partnership }\end{array}$ & 6.6 & 68.2 & 47.0 & 40.9 & & yes & & yes & \\
\hline $\begin{array}{l}\text { Leicestershire } \\
\text { Partnership }\end{array}$ & 6.6 & 68.0 & 52.8 & & & yes & & & yes \\
\hline $\begin{array}{l}\text { Northumberland, } \\
\text { Tyne \& Wear }\end{array}$ & 6.5 & 70.8 & 55.8 & 40.5 & & yes & & yes & \\
\hline $\begin{array}{l}\text { Cornwall } \\
\text { Partnership }\end{array}$ & 5.8 & 62.2 & 62.2 & & 99.0 & no & yes & & \\
\hline $\begin{array}{l}\text { Devon } \\
\text { Partnership }\end{array}$ & 5.5 & 64.2 & 65.5 & 34.5 & & & & & \\
\hline $\begin{array}{l}\text { Coventry \& } \\
\text { Warwickshire } \\
\text { Partnership }\end{array}$ & 5.5 & 50.9 & 53.3 & 29.7 & & yes & yes & yes & yes \\
\hline $\begin{array}{l}\text { Lancashire } \\
\text { Care }\end{array}$ & 4.9 & 65.9 & 60.1 & 46.2 & & no & & yes & \\
\hline $\begin{array}{l}\text { Birmingham \& Solihull } \\
\text { Mental Health }\end{array}$ & 4.3 & 56.1 & 73.5 & 59.4 & & no & & no & \\
\hline Humber & 4.1 & 68.9 & 63.5 & & 0 & & & & \\
\hline Oxford Health & 3.7 & 75.1 & 62.7 & 48.6 & & & & & \\
\hline $\begin{array}{l}\text { Somerset } \\
\text { Partnership }\end{array}$ & 3.7 & 56.7 & 58.3 & & & & & & \\
\hline $\begin{array}{l}\text { Barnet, Enfield \& } \\
\text { Haringey Mental } \\
\text { Health }\end{array}$ & 3.4 & 63.7 & 75.5 & 34.3 & & yes & & no & \\
\hline $\begin{array}{l}\text { Greater Manchester } \\
\text { West Mental Health }\end{array}$ & 3.2 & 59.5 & 31.0 & 28.4 & 90.0 & yes & yes & yes & yes \\
\hline $\begin{array}{l}\text { Hertfordshire } \\
\text { Partnership University }\end{array}$ & 3.0 & 66.7 & 50.0 & 72.2 & 100 & & & & \\
\hline $\begin{array}{l}\text { Bradford } \\
\text { District }\end{array}$ & 3.0 & 51.9 & 55.8 & 26.9 & 69.2 & yes & & yes & \\
\hline $\begin{array}{l}\text { Cambridgeshire \& } \\
\text { Peterborough }\end{array}$ & 2.8 & & & 37.5 & & yes & & yes & \\
\hline
\end{tabular}




\begin{tabular}{|c|c|c|c|c|c|c|c|}
\hline $\begin{array}{l}\text { S Staffordshire \& } \\
\text { Shropshire Health }\end{array}$ & 2.5 & 85.7 & 82.1 & & 0 & no & no \\
\hline S London \& Maudsley & 2.5 & & & 37.1 & & & \\
\hline Camden \& Islington & 2.3 & 66.7 & 22.2 & 60.0 & 100 & no & no \\
\hline $\begin{array}{l}\text { Kent \& Medway NHS \& } \\
\text { Social Care Partnership }\end{array}$ & 2.1 & 59.4 & 41.5 & 46.2 & 100 & no & no \\
\hline $\begin{array}{l}\text { West London Mental } \\
\text { Health }\end{array}$ & 2.0 & 72.1 & 39.5 & 51.2 & 100 & yes & yes \\
\hline $\begin{array}{l}\text { SW London \& St } \\
\text { George's Mental } \\
\text { Health }\end{array}$ & 1.2 & 48.8 & 41.5 & & & no & no \\
\hline $\begin{array}{l}\text { Black Country } \\
\text { Partnership }\end{array}$ & 1.0 & 70.8 & 50 & 100 & & yes & \\
\hline $\begin{array}{l}\text { Manchester Mental } \\
\text { Health \& Social Care }\end{array}$ & $\mathrm{a}$ & 67.8 & 50.8 & 44.1 & & no & yes \\
\hline Mersey Care Trust & $b$ & 67.2 & 64.8 & 35.2 & 82.0 & no & yes \\
\hline Weighted Average \% & & 66.1 & 56.5 & 38.7 & 72.6 & & \\
\hline
\end{tabular}

$\mathrm{a}=$ Trust now subsumed into Greater Manchester West MHT; population data not available.

$b=$ reliable population data not available.

Empty cell $=$ no response $/$ data not available. 